1 Population Health Sciences Institute, Newcastle University, Newcastle upon Tyne, UK

2 School of Health Sciences, City, University of London, London, UK

Correspondence to: P Roderick peter.roderick@newcastle.ac.uk Cite this as: BMJ2020;369:m2484 http://dx.doi.org/10.1136/bmj.m2484 Published: 26 June 2020

\section{Getting back on track: control of covid-19 outbreaks in the community}

Peter Roderick, Alison Macfarlane, and Allyson M Pollock argue there's still time to change tack on the UK's ad hoc system for covid-19 tracking, testing, and contact tracing

\section{Peter Roderick, ${ }^{1}$ Alison Macfarlane, ${ }^{2}$ Allyson M Pollock}

Historically, England's system of communicable disease control has relied on close cooperation between local health services and authorities. General practitioners, NHS and public health laboratories, and local public health officers play key roles, backed by legal notification requirements.

That local system has gradually been eroded over several decades. (box 1) But instead of prioritising and rebuilding this system at the start of this epidemic, the government has created a separate system which steers patients away from GPs, avoids local authorities, and relies on commercial companies and laboratories to track, test, and contact trace. The ad hoc parallel system in England has three components:

Box 1: Erosion of local communicable disease control in England

At its height, local communicable disease control was supported by more than 60 national, regional, and local public health laboratories. The service was strengthened from 1977-2002 by the creation of the Communicable Disease Surveillance Centre in Colindale.

Erosion began after NHS reorganisation in 1974 and continued when the Public Health Laboratory Service Board was abolished in 2003 and its local laboratories transferred to NHS trusts, at the same time as communicable disease control was centralised in the Health Protection Agency.

In 2012, the Health and Social Care Act abolished locally based bodies in England and carved public health functions out of the NHS. Public Health England was set up as an executive agency to fulfil the government's duty to protect the public from disease, with only nine laboratories and eight regional centres. Local authorities were charged with improving public health. Each local authority was required, acting jointly with the secretary of state, to appoint a director of public health, with responsibility for exercising the authority's public health functions.

- Covid-19 primary care programme which, until 29 May 2020, did not include information on need to notify suspected cases to local authorities

- Centralised testing programme that relies heavily on private companies

- Centrally led contact tracing system that uses commercial call centres and may in future use a mobile phone app.

We question why the government has created this ad hoc parallel system when a straightforward, if weakened, system already existed. In addition, we are concerned by apparent failings in this parallel system. The notification system (table 1) seems to have been mishandled from the beginning, and many suspected cases will have been missed as a result. Outsourced private testing services have been given the bulk of government business, with no clear public health standards. There is also a lack of clarity on where the results are being sent. 


\begin{tabular}{|c|c|c|c|}
\hline Data type & Notifier & Notified & Timescale \\
\hline \multicolumn{4}{|l|}{ England } \\
\hline Suspected cases and deaths & Registered medical practitioner & $\begin{array}{l}\text { Proper office of local authority, who then informs Public } \\
\text { Health England }\end{array}$ & $\begin{array}{l}3 \text { days (written) or, if urgent, orally as soon as } \\
\text { reasonably practicable (for each body) }\end{array}$ \\
\hline Confirmed cases and deaths & Operator of a diagnostic laboratory & Public Health England & $\begin{array}{l}7 \text { days (written) or, if urgent, orally as soon as } \\
\text { reasonably practicable }\end{array}$ \\
\hline \multicolumn{4}{|l|}{ Scotland } \\
\hline Suspected cases and deaths & Registered medical practitioner & $\begin{array}{l}\text { Health board, which then informs the Common Services } \\
\text { Agency and Public Health Scotland }\end{array}$ & $\begin{array}{l}\text { Health board: } 3 \text { days (written) for health board or, if } \\
\text { urgent, orally as soon as reasonably practicable } \\
\text { PHS: no later than the end of the week in which the } \\
\text { information is received or as soon as practicable } \\
\text { afterwards }\end{array}$ \\
\hline Confirmed cases and deaths & Director of a diagnostic laboratory & $\begin{array}{l}\text { Health board in whose area the laboratory is situated, } \\
\text { Common Services Agency, and Public Health Scotland }\end{array}$ & $\begin{array}{l}10 \text { days (written), or, if urgent, orally as soon as } \\
\text { reasonably practicable }\end{array}$ \\
\hline \multicolumn{4}{|l|}{ Wales } \\
\hline Suspected cases and deaths & Registered medical practitioner & $\begin{array}{c}\text { Proper officer of local authority, who then informs Public } \\
\text { Health Wales }\end{array}$ & $\begin{array}{l}3 \text { days (written), of, if urgent, orally as soon as } \\
\text { reasonably practicable (for each body) }\end{array}$ \\
\hline Confirmed cases and deaths & Operator of a diagnostic laboratory & $\begin{array}{l}\text { Proper officer of local authority, who then informs Public } \\
\text { Health Wales }\end{array}$ & $\begin{array}{l}\text { Local authority: } 3 \text { days (written) or, if urgent, orally as } \\
\text { soon as reasonably practicable } \\
\text { PHW: } 3 \text { days (written), or, if urgent, orally as soon as } \\
\text { reasonably practicable }\end{array}$ \\
\hline \multicolumn{4}{|l|}{ Northern Ireland } \\
\hline $\begin{array}{l}\text { Suspected and confirmed cases and } \\
\text { deaths }\end{array}$ & Medical practitioner & Director of public health for Northern Ireland & As soon as suspected or confirmed \\
\hline
\end{tabular}

Sources: England: The Health Protection (Notification) Regulations 2010, Regulations 2, 3, 4, and 6; Scotland: Public Health etc (Scotland) Act 2008, sections 13, 15, and 16, as amended; Wales: The Health Protection (Notification) (Wales) Regulations 2010, Regulations 2, 3, 4, and 6; Northern Ireland: Public Health Act (Northern Ireland) 1967, section 2, as amended.

\section{Notification of suspected cases}

SARS-CoV-2 was declared a serious and imminent threat to public health on 10 February $2020,{ }^{1}$ but covid-19 was added to the list of notifiable diseases only on 5 March. ${ }^{2}$ From the outset, the notification system was inadequate.

NHS 111 covid-19 call centres were hastily set up. Symptomatic patients were advised to stay at home and not contact their GPs or NHS 111 initially, ${ }^{3}$ and thereafter to contact NHS 111 online. This will have prevented rapid reporting of suspected cases. A covid-19 clinical assessment service was also set up to receive and possibly reclassify referrals after NHS 111 triaging, using retired and locum or sessional GPs instead of general practices. It is not known whether registered medical practitioners working in NHS 111 or the assessment service notified any suspected cases.

NHS guidance ${ }^{4}$ did not alert GPs to the need to inform local authorities of suspected cases. It advised GPs to inform Public Health England (PHE) of symptomatic cases and then only in specified settings or unusual scenarios. The guidance also wrongly implied that the requirements relating to notifiable diseases apply only to confirmed cases. These failings were only partially rectified in new guidance dated 29 May 2020. ${ }^{5}$ PHE's guidance wrongly implies that local authorities do not need to be notified of suspected cases. ${ }^{6}$

\section{Centralised and commercially run tests}

A public health approach to testing requires a clear purpose, systematic delivery and data flows, informed participation, quality assurance, equity, and ethical oversight to build trust. Decisions should be safeguarded from political and commercial interference. ${ }^{7}$ The testing programme announced by the government on 4 April $2020^{8}$ with its "five pillars" falls well short of what is required.

Instead of focusing on increasing capacity in PHE and NHS laboratories, which report results to PHE through its second generation surveillance system, the government designated these laboratories as "pillar 1 " for people with a clinical need and health and care workers and set up a separate, centralised, and commercially based "pillar 2" for the wider population.

Daily numbers of pillar 1 tests have levelled off, and numbers of pillar 2 tests now tend to exceed those for pillar $1 .{ }^{9}$ They include in-person tests, which are counted when samples are taken at testing stations at about 50 regional sites and mobile testing units run by the army. Testing kits posted out to people at home and elsewhere are counted on dispatch, ${ }^{10}$ and it is not known how many are actually used. Numbers have increased dramatically on some occasions when the government has been trying to reach preset targets for testing. ${ }^{11}$

The president of the Institute of Biomedical Science has described creating this new additional structure as "perverse," competing with NHS laboratories and freezing them out. ${ }^{12}$

Pillar 2 is based on contracts with commercial companies. Very few appear on the government's contracts finder website. It seems from the list of data processors, ${ }^{13}$ which has changed frequently, that testers at regional sites are provided by Sodexo and Boots; some sites are operated by Deloitte. Serco, G4S, and Levy provide facilities management. Randox provides home testing kits, the logistics for which are provided by Amazon.

Pillar 2 samples are analysed by the four new "lighthouse labs," which involve AstraZeneca and GlaxoSmithKline (box 2), even though both state that "diagnostic testing is not part of either company's core business." 1516 Randox analyses the samples from its home test kits, with a contract for £133m (€150m; \$165m). ${ }^{17}$ This compares with the $£ 86.9 \mathrm{~m}$ provided to PHE for infectious disease, surveillance, and outbreak management in 2018-19. ${ }^{18}$ In all, 67000 Randox tests are reported to have been sent to the US for analysis 
because of lack of capacity, but 29500 results were found to be invalid and needed to be redone. ${ }^{19}$

Box 2: Lighthouse laboratories ${ }^{14}$

- Milton Keynes-managed by UK Biocentre, the largest facility in the UK for storing and processing biological samples. It is the trading subsidiary of the charity UK Biobank

- Alderley Park is a life science campus with a dedicated lab for covid-19 analysis led by Medicines Discovery Catapult, which was set up as a limited company with a grant from Innovate UK to support drug companies, contract research organisations, and diagnostic businesses operating in the health sector

- Glasgow-the lab is led by the University of Glasgow at the city's Queen Elizabeth University Hospital. It is supported by the Scottish Government, BioAscent Discovery (a provider of integrated drug discovery services), and the University of Dundee

Cambridge-a collaboration between AstraZeneca, GSK, and the University of Cambridge's Anne McLaren laboratory

According to the government, ${ }^{13}$ results of non-Randox tests are sent to the National Pathology Exchange (NPEx) hosted by Calderdale and Huddersfield NHS Foundation Trust. NPEx links them to test registration and passes results to NHS Digital and to the NHS Business Services Authority, which sends results to those who have been tested. The government also states that Palantir analyses anonymised data. ${ }^{13}$

The strategy has three further pillars. Pillar 3 is mass antibody testing. Pillar 4 is a programme of serology and swab testing for national surveillance supported by PHE, the Office for National Statistics, UK Biobank, universities, and other partners. The aim of Pillar 5 is to build a British diagnostics industry, with the short term aim of supplying the other pillars.

\section{Feedback of results}

It is unclear what happens to many test results, in particular whether they are fed back to individual patients' GPs. Several hundred thousand tests are reported not to have been linked to NHS records, missing confirmed cases. ${ }^{20}$ There is also no indication whether results are made available to staff doing local contract tracing. The chief medical officer for England is reported to have apologised to local authorities for not having detailed data from tests conducted by Deloitte. ${ }^{21}$ It is unclear whether PHE has timely access to test outcomes.

Further problems have arisen in relation to reporting numbers of tests and results in national statistics, prompting two letters to the secretary of state for health and social care from David Norgrove, chair of the UK Statistics Authority. ${ }^{22} 23$ The second suggested that the statistics should enable an understanding of the epidemic and help manage the testing programme but pointed out that "the statistics and analysis serve neither purpose well" and that the main aim seemed to be to claim the largest possible numbers of tests.

\section{Centralised and commercially run contact tracing}

Contact tracing is a local activity. Local authorities know their community, and tracing requires feet on the ground. But the tracing programme announced by the secretary of state on 23 April $2020^{24}$ is centralised, using call centres operated by Serco and other companies with thousands of newly recruited call handlers. The programme may not be fully operational until September. ${ }^{25}$ The NHS covid-19 app, which had been touted as key to contact tracing, has now been abandoned.
It is unclear how the contact tracing programme will operate, as outbreak management plans are yet to be produced. The government's guidance does not mention GPs or local directors of public health. ${ }^{26}$ It is not known whether, how, or to whom suspected cases will be notified. Inefficiency, data quality issues, local data access difficulties, and unnecessary expense are inevitable.

Details such as full postcodes, and age and sex of suspected and confirmed cases are essential for monitoring outbreaks in a local authority area and identifying clusters. However, local authorities do not have live access to this information and are instead sent aggregated data. This approach, combined with the failures to require notification of suspected cases and to undertake community testing, has further hampered outbreak control. Instead of restoring local data flows, the government is attempting to create a population surveillance system through the new Joint Biosecurity Centre. ${ }^{27}$ The centre will receive data from numerous sources, including NHS data through the portal of NHSX's covid-19 data store reference library. Over 50 datasets are being integrated and harmonised by private data companies Palantir and Faculty to create a "single source of truth."28

\section{Making it work}

Immediate steps should be taken to ensure that registered medical practitioners within NHS 111, the covid-19 assessment service, and general practice notify local authorities of suspected cases. Outbreak management plans should put local directors of public health in control of contact tracing, coordinated rather than led by PHE. The capacity of the NHS 111 covid-19 call centres and the assessment service should be immediately reintegrated into primary care and practices resourced to resume care. Official advice to those with covid-19 symptoms should be amended to direct them to contact a GP or NHS 111.

These steps, however, are remedial. They do not amount to a coherent and adequate public health response to the epidemic in England. Such a response requires local authorities, NHS, and PHE laboratories to be sufficiently resourced to take the lead on contact tracing and testing, and general practices being resourced to support patients, under central coordination. Parliament has given the secretary of state the powers to enable this to happen, and we urge him to exercise them.

In the longer term, the abysmal response of the government to the epidemic has served to underline the need for legislation to rebuild and reintegrate a strong local communicable disease control system.

\section{Key messages}

- England's established system of local communicable disease control has been eroded over several decades

- In response to covid-19 the government has created a parallel system which steers patients away from GPs and relies on commercial companies for testing and contact tracing

- Many suspected cases will have been missed because of mishandling of the notification system

- NHS 111 covid-19 call centres and the covid-19 clinical assessment service should be reintegrated immediately into primary care and practices resourced to resume care

- Contact tracing and testing should be led by local authorities and coordinated nationally

- England must rebuild and reintegrate its local communicable disease control system 
of experience of researching public health policy and the privatisation of the NHS and long term care. She is a member of Independent SAGE; the views expressed here are her own. AM is a perinatal epidemiologist and statistician with over 40 years of experience of researching public health and health service policy. PR researched the statutory provisions. All authors researched the operation of the notification system in practice and the testing programme. AM and PR researched the history of local communicable disease control. PR wrote the first draft of the article and all authors were involved in further drafting and editing. We gratefully acknowledge helpful discussions with several local public health practitioners and GPs during the preparation of this article.

Competing interests: We have read and understood BMJ policy on declaration of interests and have no relevant interests to declare.

Provenance and peer review: Not commissioned; externally peer reviewed.

1 Secretary of State makes new regulations on coronavirus. 10 Feb 2020. www.gov.uk/government/news/secretary-of-state-makes-new-regulations-on-coronavirus\#

2 Health Protection (Notification). (Amendment) Regulations 2020. http://www.legislation.gov.uk/uksi/2020/237/made

3 Public Health England. Guidance. Stay at home: guidance for households with possible coronavirus (COVID-19) infection. 18 May 2020. https://www.gov.uk/government/publications/Covid-19-stayat-home-guidance/stay-at-home-guidance-for-households-with-possible-coronavirus-Covid-19infection

$4 \quad$ NHS England, NHS Improvement. Guidance and standard operating procedures - general practice in the context of coronavirus (COVID-19). Publications approval reference: 001559. 6 April 2020, Version 2.1, section 4.2, page 11.

https://web.archive.org/web/20200426114124/https://www.england.nhs.uk/coronavirus/wpcontent/uploads/sites/52/2020/03/C0133-COVID-19-Primary-Care-SOP-GP-practice_V2.1_6April.pdf

5 NHS England, NHS Improvement. Guidance and standard operating procedures - general practice in the context of coronavirus (COVID-19). Publications approval reference: 001559. 29 May 2020, Version 3; replaced by Version 3.2. 10 June 2020. https://www.england.nhs.uk/coronavirus/wp-content/uploads/sites/52/2020/03/CO485_guidance-and-standard-operating-procedures-general-practice-covid-19.pdf

6 Public Health England. Guidance. Notifiable diseases and causative organisms: how to report. 9 March 2020. https://www.gov.uk/guidance/notifiable-diseases-and-causative-organisms-howto-report

7 Raffle AE, Mackie A, Gray M. Screening; evidence and practice. 2nd ed. Oxford University Press, 2019.

8 Department of Health and Social Care. Coronavirus (COVID-19) Scaling up our testing programmes. 4 April 2020. https://www.gov.uk/government/publications/coronavirus-covid-19-scaling-uptesting-programmes

9 Department of Health and Social Care. Number of coronavirus (COVID-19) cases and risk in the UK. 6 June 2020. https://www.gov.uk/guidance/coronavirus-covid-19-information-for-the-public

10 Department of Health and Social Care. Guidance. COVID-19 testing data: methodology note. 2 June 2020. https://www.gov.uk/government/publications/coronavirus-covid-19-testing-datamethodology/covid-19-testing-data-methodology-note

11 Testing statistics. https://www.gov.uk/guidance/coronavirus-covid-19-information-for-the-public

12 NHS labs were frozen out of coronavirus testing programme, says top scientist. Huffington Post 2020 May 14. https://www.huffingtonpost.co.uk/entry/nhs-labs-coronavirus-testing_uk_5ebd3f78c5b6078ff41d28dc?guccounter=1

13 Department of Health and Social Care. Testing for coronavirus: privacy information. Guidance. 3 June 2020. https://www.gov.uk/government/publications/coronavirus-Covid-19-testing-privacyinformation/testing-for-coronavirus-privacy-information

14 UK Lighthouse Labs Network. 2020. https://www.lighthouselabs.org.uk/

15 AstraZeneca. AstraZeneca/GSK/University of Cambridge collaborate to support UK national effort to boost COVID-19 testing. Press release, 7 Apr 2020. https://www.astrazeneca.co.uk/mediapress-releases/2020/astrazeneca-gsk-university-of-cambridge-collaborate-to-support-uk-nationaleffort-to-boost-Covid-19-testing.html

16 GSK. Supporting UK national effort to boost COVID-19 testing. Press release, 7 Apr 2020. https:/www.gsk.com/en-gb/media/resource-centre/our-contribution-to-the-fight-against-2019ncov/supporting-uk-national-effort-to-boost-Covid-19-testing/

17 UK government. Contracts finder. https://www.contractsfinder.service.gov.uk/Notice/7f989fa6 30e6-4caa-b28f-2b98fcce21c4?origin=SearchResults \& $p=1$

18 Public Health England. Annual report and accounts 2018/19. https://www.gov.uk/government/publications/phe-annual-report-and-accounts-2018-to-2019

19 Almost 30,000 invalid UK coronavirus tests had to be redone. Guardian 2020 Jun 4. https://www.theguardian.com/world/2020/jun/04/almost-30000-invalid-uk-coronavirus-testshad-to-be-redone

20 Coronavirus testing hit by struggle to match results with NHS records. Guardian 2020 May 28. https://www.theguardian.com/world/2020/may/28/coronavirus-testing-hit-struggle-match-resultswith-nhs-records

21 We have had zero information": GPs in the dark over Covid-19 tests. Guardian 2020 May 6. https://www.theguardian.com/world/2020/may/06/we-have-had-zero-information-gps-in-thedark-over-Covid-19-tests
22 Norgrove D. Letter to Matt Hancock regarding COVID-19 testing 11 May 2020. https://www.statisticsauthority.gov.uk/correspondence/sir-david-norgrove-letter-to-matt-hancock regarding-Covid-19-testing/

23 Norgrove D. Response to Matt Hancock regarding the government's COVID-19 testing data. 2 June 2020. https://www.statisticsauthority.gov.uk/correspondence/sir-david-norgrove-responseto-matt-hancock-regarding-the-governments-Covid-19-testing-data/

24 Secretary of State for Health and Social Care. Statement on coronavirus (COVID-19). 23 April 2020. https://www.gov.uk/government/speeches/health-and-social-care-secretarys-statementon-coronavirus-Covid-19-23-april-2020

25 NHS test-and-trace system “not fully operational until September." Guardian 2020 Jun 4. https://www.theguardian.com/society/2020/jun/04/nhs-track-and-trace-system-not-expectedto-be-operating-fully-until-september-coronavirus

26 Department of Health and Social Care. Guidance. NHS test and trace: how it works. 11 June 2020. https://www.gov.uk/guidance/nhs-test-and-trace-how-it-works

27 Cabinet Office. Guidance. Our plan to rebuild: the UK Government's COVID-19 recovery strategy. 12 June 2020. https://www.gov.uk/government/publications/our-plan-to-rebuild-the-uk-governments-Covid-19-recovery-strategy/our-plan-to-rebuild-the-uk-governments-Covid-19-recovery strategy

28 NHS. COVID-19 Data store reference library. 11 June 2020. https://data.england.nhs.uk/covid-19/

This article is made freely available for use in accordance with BMJ's website terms and conditions for the duration of the covid-19 pandemic or until otherwise determined by BM]. You may use, download and print the article for any lawful, non-commercial purpose (including text and data mining) provided that all copyright notices and trade marks are retained. 